\title{
Simulations about the effect of heat treatment temperatures on the properties of diffusion bonded Mg/Al joints
}

\author{
Yunlong Ding ${ }^{1}$, Jiangang Wang ${ }^{2}$ and Dongying $\mathrm{Ju}^{3,4, a}$ \\ ${ }^{1}$ Graduate School of Saitama Institute of Technology, Fusaiji 1690, Fukaya, Saitama 369-0293, Japan, e5002Imf@sit.ac.jp \\ ${ }^{2}$ Hebei Key Laboratory of Material Near-Net Forming Technology, Hebe University of Science and Technology, Hebei Shijiazhuang \\ 050018, China,wm094212@163.com \\ ${ }^{3}$ Department of Material Science and Engineering, University of Science and Technology Liaoning, Anshan 114051, China \\ ${ }^{4}$ Department of Material Science and Engineering, Saitama Institute of Technology, Fusaiji 1690, Fukaya, Saitama 369-0293, \\ dyju@sit.ac.jp
}

\begin{abstract}
In this study, Finite elements method (FEM) was used for simulations on the annealing treatment. And the distributions of residual stress were obtained from the resualts of simulitions. Besides, in order to study the mechanical properties. Composite plates of AZ31B magnesium alloys and 6061 aluminum alloys were fabricated by vacuum diffusion bonding method. Then experiments about annealing, measurement of residual stresses and tension test were also carried out. The results of residual stresses obtained by X-ray diffraction (XRD) were compared with the results of simulations. It can be thought that the results of residual stress obtained from simulations and that from experiments are in a good agreement. What's more, The residual stress after annealing at $250^{\circ} \mathrm{C}$ is the least of all, while the tensile strength is the strongest. On the basis of results of simulations and experiments, the conclusion can be obtained that $250^{\circ} \mathrm{C}$ is the most appropriate annealing temperature.
\end{abstract}

\section{Introduction}

Magnesium is the lightest metal [1]. As the use of magnesium alloys, the weight of components can be reduced significantly. However, it's corroded easily. While aluminum alloys have attractive mechanical and metallurgical properties, including high strength and excellent corrosion resistance [2]. So wide and cross applications of these two metals make the connection of $\mathrm{Mg} / \mathrm{Al}$ dissimilar metals inevitable[3]. For example, the $\mathrm{Mg}$-Al laminated armor is used in tanks and armored vehicles[4], $\mathrm{Mg} / \mathrm{Al}$ complex structure is used in aerospace engines and components[5,6,7]. So it is significant to achieve reliable connection of $\mathrm{Mg} / \mathrm{Al}$ dissimilar metals. Presently, there are many studies about welding of magnesium and aluminium. And there are many welding methods that have been used to join $\mathrm{Mg}$ alloys and Al alloys. However, no matter which technique is used, if the brittle and hard intermetallic compounds, such as $\mathrm{Al}_{3} \mathrm{Mg}_{2}$ and $\mathrm{Mg}_{17} \mathrm{Al}_{12}$ were formed in the joints. The performances of welded joints will be deteriorated seriously[8].

In this study, for the purpose of improving the tensile strength, simulations on annealing treatment were applied to search for the apposite annealing temperature. Besides, experiments on annealing treatment were also carried out What's more, residual stress and tensile strength were investigated in this work.

\section{Simulations}

During the processes of diffusion bonding and heat treatment, along with the change of temperature, microstructure will transform, and at the same time, thermal stress emerges. If the stress exceeds the elastic limit, plastic deformation will result from it. A series of varieties don't emerge individually but interact on each other. The theory system related is constructed and called metallo-thermo-mechanics, which is the foundation of thermal treatment analysis.

\footnotetext{
${ }^{a}$ Corresponding author: Prof. Dongying Ju, E-mail: dyju@sit.ac.jp, Tel: 81-48-5856826, Fax: 81-48-5855928
} 
When AZ31 magnesium alloy and 6061 aluminum alloy is joined by the method of diffusion bonding, diffusion between the elements $\mathrm{Mg}$ and $\mathrm{Al}$ should be considered. Diffusion phenomenon can be analyzed by Fick's law and expressed as the following equation:

$$
\frac{\partial C}{\partial t}=D \frac{\partial^{2} C}{\partial x^{2}}
$$

Where $C$ is the concentration of element, $D$ which is a function of $C$, is diffusion coefficient standing for the diffusion property of material, and can be express using the following equation:

$$
D=K_{0} \exp \left(K_{1} C\right)
$$

Where $K_{0}$ and $K_{1}$ are coefficients. Generally speaking, if the influence resulted from the variety of microstructure is ignored, the diffusion equation can be expressed with the element's concentration $C$ :

$$
\dot{C}=\operatorname{div}(\operatorname{Dgrad} C)
$$

The boundary condition is represented as the following equation:

$$
-D_{c} \operatorname{grad} C \cdot n=\beta_{c}\left(C-C_{w}\right)
$$

Where $\beta_{c}$ is the concentration of gas around, $C_{w}$ is the concentration of elements around.

If the energy in objects is represented as $e=g+\operatorname{Tr}+\operatorname{tr}\left(\sigma \varepsilon^{e}\right)$, then the first law of thermodynamics can be wrote as :

$$
\rho \dot{e}-\operatorname{tr}(\sigma \dot{\varepsilon})+\operatorname{div} \boldsymbol{h}=0
$$

If Fourier law ( $\boldsymbol{h}=\mathrm{kgrad} T$ ) is used, plastic work and transformation latent heat is not considered, items that relate elastic strain and hardening coefficient are ignored, then equation (5) can be wrote as the following equation:

$$
\rho c \dot{T}-k d i v(\operatorname{grad} T)=0
$$

Where $\rho$ is the density of material, $c$ is specific heat, $k$ is thermal conductivity. When the coefficient of heat transfer and the temperature of fluid that is in touch with the objects are changeless, boundary condition is expressed using the following equation:

$$
-\operatorname{kgrad} T \cdot \boldsymbol{n}=h(T)\left(T-T_{\omega}\right)
$$

Where $\boldsymbol{n}$ is a vector whose direction is outward from the surface of objects. $T_{\omega}$ is temperature around. $h(T)$ is the coefficient of heat transfer between object and environment. Generally, coefficient of heat transfer is a function of temperature $T$, which can be obtained from the experiment value of cooling curve [9].

When plastic materials are with load, elastic or plastic deformation will occur. The generalized Hooke's law is applicable to three-dimensional stress and strain, and can be expressed using the equation (8):

$$
\dot{\varepsilon_{i j}}=\dot{\varepsilon^{e}}+\dot{\varepsilon}_{i j}^{p}+\dot{\varepsilon}_{i j}^{T}
$$

Where $\dot{\varepsilon}_{i j}$ is total strain rate, $\dot{\varepsilon}^{e}$ is elastic strain rate, $\dot{\varepsilon}_{i j}^{p}$ is plastic strain rate, and $\dot{\varepsilon}_{i j}^{T}$ is thermal strain rate. Especially, elastic strain rate and thermal strain rate are expressed with the following equation.

$$
\left\{\begin{array}{l}
\dot{\varepsilon}_{i j}^{e}+\dot{\varepsilon}_{i j}^{T}=E_{i j k l}^{e} \dot{\sigma}_{k l}+\beta_{i j} \dot{T} \\
\beta_{i j}=\frac{\partial E_{i j k l}^{e}}{\partial T} \sigma_{k l}+\alpha_{i j} \frac{\partial \alpha_{i j}}{\partial T}\left(T-T_{0}\right)
\end{array}\right.
$$

Where $\alpha$ is linear expansion coefficient, and is temperature difference. $E_{i j k l}^{e}$ is a coefficient that is represented as equation (10):

$$
E_{i j k l}^{e}=\frac{1}{2 G}\left\{\left(\delta_{i k} \delta_{j l}+\delta_{i l} \delta_{j k}\right)-\frac{v}{1+v} \delta_{i j} \delta_{k l}\right\}
$$

Where $v$ and $G$ are Poisson's ratio and shear modulus [19]. Plastic strain rate is expressed as equation (11):

$$
\left\{\begin{array}{l}
\varepsilon_{i j}^{p}=\frac{1}{\hat{G}}\left(\frac{\partial F}{\partial \sigma_{m n}} \sigma_{m n}+\frac{\partial F}{\partial T} T\right) \frac{\partial F}{\partial \sigma_{i j}} \\
\frac{1}{\hat{G}}=-\frac{1}{\frac{\partial F}{\partial \kappa} \frac{\partial F}{\partial \sigma_{k l}} \sigma_{k l}} \\
F=F(\sigma, T)
\end{array}\right.
$$

Where $F$ is Mises yield function.

First, the definitions of mixture and maxing rule are explained. Intermetallic compounds, such as $\mathrm{Al}_{3} \mathrm{Mg}_{2}$ and $\mathrm{Mg}_{17} \mathrm{Al}_{12}$ will generate during the diffusion process of magnesium alloy and aluminum alloy. It is thought that there are many micro-structures mix together. Mixture contains $N$ compositions whose volume fraction are $\xi_{I}(I=1,2, \cdots \cdots, N)$, and if all the volume fractions are together, then 1 will be obtained. It can be expressed as:

$$
\sum_{I=1}^{N} \xi_{I}=1
$$

If the property of composition $I$ is represented by $\chi_{I}$, then the property $\chi$ contains all the properties of $N$ compositions. Therefore, the property $\chi$ can be expressed as equation (13), which is called maxing rule [10].

$$
\chi=\sum_{I=1}^{N} \chi_{I} \xi_{I}, \quad \xi_{I}(I=1,2, \cdots \cdots, N)
$$

According to the maxing rule, the coefficients of AZ31 magnesium alloy and 6061 aluminum alloy, and all the coefficients that relate the Intermetallic compounds of $\mathrm{Mg}$ and $\mathrm{Al}$ are calculated. Then simulations were carried out. Temperature conditions were $200^{\circ} \mathrm{C}, 250^{\circ} \mathrm{C}, 300^{\circ} \mathrm{C}$ and room temperature $20^{\circ} \mathrm{C}$. It was thought that the interface can't move during diffusion process. Therefore, 
restrict was only applied to the contact surface, so that it can't move any directions. Then simulations were carried out.

\section{Experimental}

AZ31B magnesium alloy sheets and 6061 aluminum alloy sheets were successfully joined using vacuum diffusion bonding method in the equipment with atmosphere of argon. The size of sample was shown as Fig.1. The joining temperature was $440^{\circ} \mathrm{C}$ and the flowing rate of gas was set as $150 \mathrm{ml} / \mathrm{min}$. Before diffusion bonding, the oxide layers on the surfaces of substrates were cleaned using abrasive papers (GRIT 240, $600,800,1200)$ and polished with polishing cloth and polishing compound. Then the grinded sheets were wiped with acetone. After vacuum diffusion bonding, the samples were used for the annealing treatment experiments. The heat treatment temperatures were $200^{\circ} \mathrm{C} 、 250^{\circ} \mathrm{C} 、 300^{\circ} \mathrm{C}$, and the holding time was $60 \mathrm{~min}$. Then cooled down to the room temperature in the electric furnace.

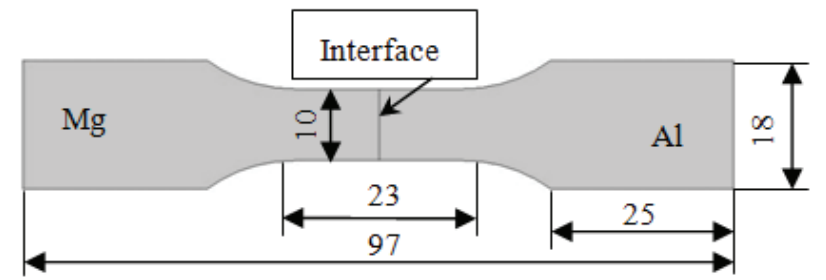

Fig.1 The size of specimen

In order to investigate the distribution of residual stress of the specimens annealed at different temperatures, residual stress was measured by XRD (X-Ray Diffraction). Based on residual stress testing principle, and used $\mathrm{x}$-ray whose wavelength was $\lambda$. First, radiate the specimen with different incident angles, and obtained the corresponding diffraction angle $2 \theta$, then the slope $M$ of $2 \theta-\sin ^{2} \psi$ (generally, $\psi$ was set as $0^{\circ} 、 15^{\circ} 、 30^{\circ} 、 45^{\circ}$ ) can be calculated. In addition, the relationship between $2 \theta$ and $\sin ^{2} \psi$ can be obtained, then residual stress $\sigma$ can be calculated according to the following equation:

$$
\sigma=K \cdot \Delta 2 \theta / \Delta \sin 2 \psi=K \cdot M
$$

Where $K$ is the stress constant of x-ray diffraction analysis, which can be expressed as:

$$
K=-\frac{1}{2} \cdot \cot \theta_{0} \cdot \frac{E}{1+v} \cdot \frac{\pi}{180}
$$

Where $E$ is the elastic modulus of material, $\theta_{0}$ is the diffraction angle without stress, $v$ is Poisson's ratio [11].

When the side of $6061 \mathrm{Al}$ alloy was measured, $2 \theta$ was set as $140^{\circ}$, stress constant was $-163.32 \mathrm{MPa} /{ }^{\circ}$, tube type was $\mathrm{Cr}$, wavelength was $\mathrm{k} \alpha$, and the size of collimator was $\varphi 0.5 \mathrm{~mm}$. While $2 \theta$ was set as $155^{\circ}$, stress constant was $-79.14 \mathrm{MPa} /{ }^{\circ}$ at the side of $\mathrm{AZ} 31 \mathrm{Mg}$ alloy. What's more, tube type, wavelength and the size of collimator were the same with $6061 \mathrm{Al}$ alloy. In addition, the $2 \theta$ of $\mathrm{Mg}_{17} \mathrm{Al}_{12}$ and $\mathrm{Al}_{3} \mathrm{Mg}_{2}$ were set as $150^{\circ}$ and $145^{\circ}$, and stress constant were respectively $-98.97 \mathrm{MPa} /{ }^{\circ}$ and -
126.22MPa/ ${ }^{\circ}$. Then the results of residual stress were calculated at last.

Besides, tensile strength was tested by using tensile machine, and there are three specimens that were annealed at the same temperature were measured in every group. During the experiment, first, the parts were regulated into the same vertical plane, and the specimen was clamped, then loaded gradually until the specimen was fractured. What's more, all the specimens were tested respectively, and the tensile strength was obtained.

\section{Results and discussions}

The results of simulations are shown in Fig.2 a, b, c and d. The distributions of residual stress obtained by simulations at different temperatures are nearly the same, but the stress values are different from each other. Because of the phenomenon of stress concentration emerges at the edge of interface, in another words, the place will fracture easily.

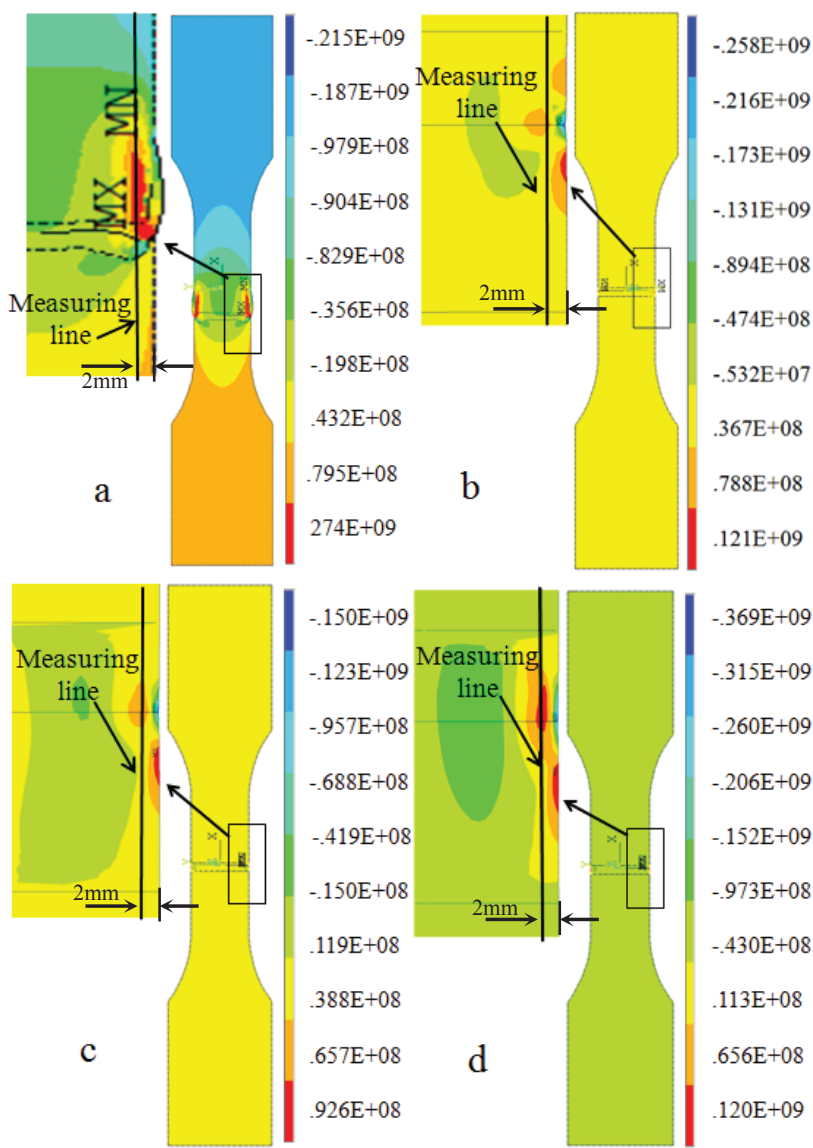

Fig.2 The results of simulations, a : without annealing, $b$ : annealing at $200^{\circ} \mathrm{C}, \mathrm{c}$ : annealing at $250^{\circ} \mathrm{C}, \mathrm{d}$ : annealing at $300^{\circ} \mathrm{C}$

In this paper, the line crossing the edge of interface and the place where stress concentration emerges was named as measuring line. The line is $2 \mathrm{~mm}$ distance from the edge(the measuring line is shown in Fig.2). Then the stress distribution along the line crossing the edge of interface and the place where stress concentration emerges was investigated. Based on the stress values at 
the places of nodes on the measuring line and the distance between nodes, Fig.3 can be got, and it shows the distribution of residual stresses that were got by simulations. It can be thought that residual stresses in the interface are tensile stress, and the values of stresses near the interface are larger than other places. The stresses near interface at the treated conditions $200^{\circ} \mathrm{C}, 250^{\circ} \mathrm{C}$, and $300^{\circ} \mathrm{C}$ are respectively $66 \mathrm{MPa}, 61 \mathrm{MPa}$ and $63 \mathrm{MPa}$. When without annealing, the stress is about $71 \mathrm{Mpa}$. In another words, The further from interface the smaller it will be. What's more, the residual stress turn to be compressive stress, when the place is far from interface and it nearly to be $0 \mathrm{MPa}$ in the further place.

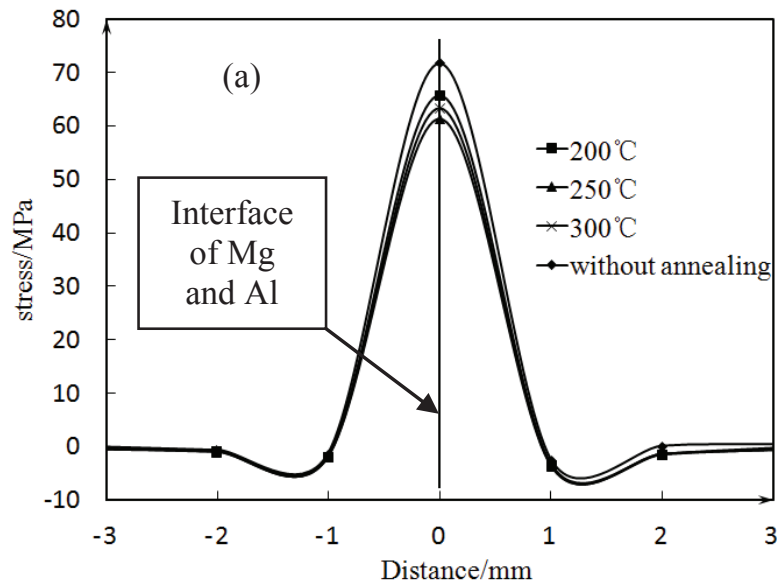

Figure.3 The distribution of residual stress, obtained by simulation

The result of residual stress measured by $\mathrm{XRD}$ is shown in Fig.4. the diffraction peak of $\mathrm{Al}$ emerges in the place where $2 \theta$ is near $139^{\circ}$, and indices of crystal face is (311). While the diffraction peak of $\mathrm{Mg}$ occurs when the value of $2 \theta$ is near $152^{\circ}$, and indices of crystal face is (104), However, the diffraction peaks of intermetallic compounds near $\mathrm{Al}$ and $\mathrm{Mg}$ are respectively $139.4^{\circ}$ and $143^{\circ}[12]$. It can be known that residual stress in the interface is tensile stress, and the value is the largest. The stress turns to be lower along with the increasing of the distance from interface. The residual stress nearly to be $0 \mathrm{MPa}$ in the further place.

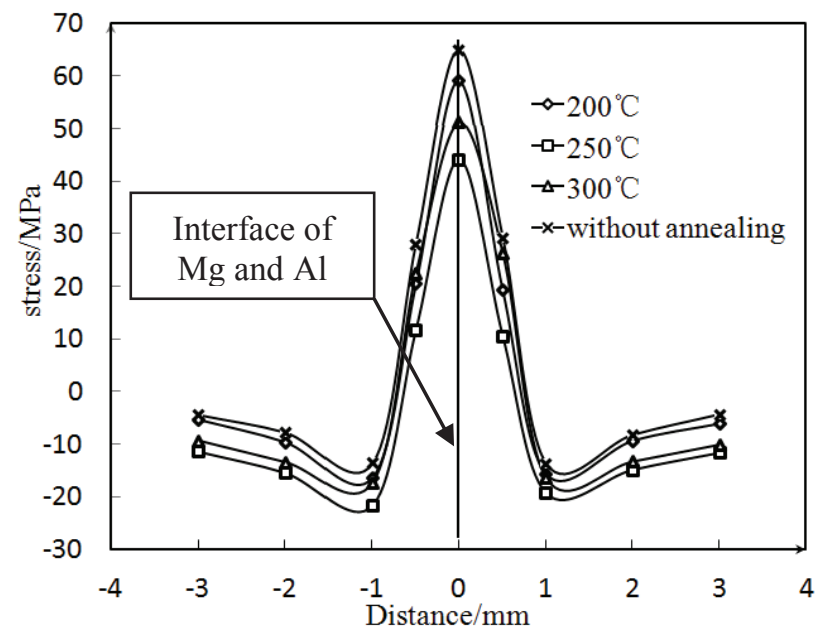

Figure.4 The distribution of residual stress, measured by XRD
In addition, when the annealing condition is $300^{\circ} \mathrm{C}$, the largest stress is about $51 \mathrm{MPa}$, when annealing temperature is $200^{\circ} \mathrm{C}$, the stress near interface is about $60 \mathrm{MPa}$, while treated at $250^{\circ} \mathrm{C}$, the largest stress is approximately 44Mpa. However, when without annealing, the stress is about $65 \mathrm{Mpa}$, which emerges at the place called interface. According to the annealing theories, The stress in the place where is far from the welded joints, turn to be smaller and smaller, and gradually close to 0 Mpa. So it could be thought that the results of residual stress obtained from simulations and experiments are in a good agreement with the welding theory.

Stress is a vector, and the tensile stress is as plus, while compressive stress is as minus in this study. When stress emerges in materials, the mechanical behavior of materials will be effected. Such as fatigue strength, tensile strength and so on. What's more, fracture will also be result in. As the study above, the residual stress in the interface of $\mathrm{Mg} / \mathrm{Al}$ alloy will effect the mechanical behavior of composite material. The bigger the residual stress is, the weaker the tensile strength will be. For the purpose of verifying the results on residual stress, the analysis about tensile strength is carried out as following.

The average tensile strengths of composite sheets treated at different annealing treatment temperature were obtained by tensile experiments. When the annealing temperature is $250^{\circ} \mathrm{C}$, the tensile strength is the strongest, which is about $47 \mathrm{MPa}$. However, when annealed at $200^{\circ} \mathrm{C}$ and $300^{\circ} \mathrm{C}$, tensile strength are approximately $41 \mathrm{MPa}$ and $39 \mathrm{MPa}$. While without annealing, the strength is about $37 \mathrm{Mpa}$, which is nearly the same with what has been reported in other study[13]. As it is known that residual stress has important impact on the strength of materials. If the residual stress is tensile tress, then it will decrease the tensile strongth of the materials and increase it's compressive strongth. In contrtast, the compressive redisual stress will decrease the compressive strongth and increase the tensile strongth of the materials. So it is apparent that the results of the experiments about tensile strength is consistent with that of residual stress.

\section{Conclusions}

In this paper, simulations about annealing of bonded $\mathrm{Mg} / \mathrm{Al}$ composite sheets, and experiments on residual stress, tensile strength were carried out. According to the outcomes of simulations and experiments, It can be thaught that the residual stress after annealing at $250^{\circ} \mathrm{C}$ is $44 \mathrm{MPa}$, which is the least of all. While the tensile strongth after annealing at $250^{\circ} \mathrm{C}$ is $47 \mathrm{Mpa}$, which is the strongest. And the results got by simulations are in a good agreement with that of experiments. So the conclusion can be obtained that $250^{\circ} \mathrm{C}$ is the most appropriate annealing temperature.

\section{Acknowledgments}

This research work has been partially supported by the grant subsidy of the "Nano Project" for Private 
Universities:2011-2014 from MEXT, Japan. This study was also supported by the "Advanced Science Research Laboratory" in Saitama Institute of Technology.

\section{References}

1. L.M. Zhao, Z.D. Zhang. Scripta Materialia. 58, 283286 (2008)

2. Y.B. Yan, Z.W. Zhang, W. Shen, J.H. Wang, L.K. Zhang, B.A. Chin. Materials Science and engineering A. 527, 2241-2245 (2010)

3. J.C. Feng, Y.R. Wang, Z.D. Zhang. The Chinese Journal of Nonferrous Metals. 15, 2 (2005)

4. H. Li, M. Qian, D. Li. Laser Journal. 28, 5 (2007)

5. J. Wang, J.C. Feng, Y.X. Wang. Mater Sci Technol. 24, 7 (2008)

6. X.R. Li, W. Liang, X.G. Zhao, Y. Zhang, X.P. Fu, F.C. Liu. Journal of Alloys and Compounds. 471, 408-411 (2009)

7. Fei Liu, Daxin Ren, Liming Liu. Materials and Design. 46 , 419-425 (2013)

8. Liming Liu, Fei Liu, Meili Zhu. Materials. 7, 2 (2014)

9. D.Y. Ju. Journal of The Society of Materials Science. 55, 7(2006)

10. T. Inoue. JSME international Journal. Ser. 1. 31, 4 (1988)

11. J.G. Wang, D.Y. Ju. Study on evolution technology of anisotropic mechanical properties and microstructure evolution of metal thin plate under complex stress condition[D], (Saitama Institute Of Technology, Japan, 2011)

12. D.Q. Zhang, J.W. He, Residual stress Analysis by xray diffraction and It's Functions, (Xi'an Jiaotong University, China, 1999)

13. J. SHANG, K.H. WANG, Q. ZHOU, D.K. ZHANG, J.HUANG, J.Q. GE. Trans. Nonferrous Met. Soc.China. 22, 1961-1966 (2012) 